\title{
The British Lexicon Project: Lexical decision data for 28,730 monosyllabic and disyllabic English words
}

\author{
Emmanuel Keuleers • Paula Lacey • Kathleen Rastle • \\ Marc Brysbaert
}

Published online: 1 July 2011

(C) The Author(s) 2011. This article is published with open access at Springerlink.com

\begin{abstract}
We present a new database of lexical decision times for English words and nonwords, for which two groups of British participants each responded to 14,365 monosyllabic and disyllabic words and the same number of nonwords for a total duration of $16 \mathrm{~h}$ (divided over multiple sessions). This database, called the British Lexicon Project (BLP), fills an important gap between the Dutch Lexicon Project (DLP; Keuleers, Diependaele, \& Brysbaert, Frontiers in Language Sciences. Psychology, 1, 174, 2010) and the English Lexicon Project (ELP; Balota et al., 2007), because it applies the repeated measures design of the DLP to the English language. The high correlation between the BLP and ELP data indicates that a high percentage of variance in lexical decision data sets is systematic variance, rather than noise, and that the results of megastudies are rather robust with respect to the selection and presentation of the stimuli. Because of its design, the BLP makes the same analyses possible as the DLP, offering researchers with a new interesting data set of wordprocessing times for mixed effects analyses and mathematical modeling. The BLP data are available at http://crr.ugent.be/blp and as Electronic Supplementary Materials.
\end{abstract}

Keywords Visual word recognition - Lexical decision . Megastudy · British English · Reaction times · Trial level analysis · Virtual experiments

Electronic supplementary material The online version of this article (doi:10.3758/s13428-011-0118-4) contains supplementary material, which is available to authorized users.

E. Keuleers $(\bowtie) \cdot$ M. Brysbaert

Department of Experimental Psychology, Ghent University,

Henri Dunantlaan 2,

B-9000 Gent, Belgium

e-mail: emmanuel.keuleers@ugent.be

P. Lacey $\cdot$ K. Rastle

Department of Psychology, Royal Holloway, University of London,

London, UK
The last decade has seen an increasing effort in creating and analyzing large data sets of behavioral word-processing data. So far, a considerable amount of word-processing data has been made available to the research community (Table 1).

These large-scale data sets have many applications, including the following:

- Continuous variables can be treated as such, allowing examination of effects over an entire range (e.g., investigating the word frequency effect is not limited to a comparison of high- vs. low-frequency words).

- The relative importance of various word and task characteristics can be determined by looking at explained variance (e.g., word frequency explains most of the variance in lexical decision times, whereas the first phoneme explains most of the variance in naming times of monosyllabic words).

- Researchers can run virtual experiments on the data set, to evaluate new hypotheses, to check the reliability and generality of their own findings, or to better control their stimulus sets.

- The word-processing data can be used to evaluate computational models of word recognition and to assess the impact and the quality of word indices (e.g., different measures of word frequency).

- Mathematical psychologists can use the data sets to test and develop models of binary decisions (e.g., by analysis of the reaction time $[\mathrm{RT}]$ distributions of lexical decisions).

As is true for all aspects of scientific research, the availability of multiple word recognition data sets is a strength rather than a weakness, since the data sets differ in task, language, and experimental design, decreasing the risk of idiosyncratic findings from a single database.

At the same time, researchers should be aware of the ways in which the data sets differ from each other. For instance, the lexical decision study performed by Balota et 
Table 1 List of visual word recognition megastudies

\begin{tabular}{|c|c|c|c|}
\hline Source & Task & Material & Participants \\
\hline Seidenberg and Waters (1989) & Naming & 2,897 monosyllabic English words & 30 students \\
\hline $\begin{array}{l}\text { Treiman, Mullenix, Bijeljac-Babic, } \\
\text { and Richmond-Welty (1995) }\end{array}$ & Naming & $\begin{array}{l}\text { 1,329 English monosyllabic CVC } \\
\text { words }\end{array}$ & 27 students \\
\hline Spieler and Balota (1997) & Naming & 2,820 monosyllabic English words & 31 students \\
\hline Spieler and Balota (2000) & Naming & 2,820 monosyllabic English words & 29 older adults (mean age $=73$ years) \\
\hline Chateau and Jared (2003) & Naming & 1,000 disyllabic six-letter words & 29 undergraduate students \\
\hline Balota et al. (2004) & Lexical decision & 2,906 English monosyllabic words & $\begin{array}{l}30 \text { students and } 30 \text { older adults } \\
\text { (mean age }=74 \text { years) }\end{array}$ \\
\hline Balota et al. (2007) & $\begin{array}{l}\text { Lexical decision and } \\
\text { naming }\end{array}$ & 40,481 English words & $\begin{array}{l}400 \text { students (naming), } 816 \text { students } \\
\text { (lexical decision) }\end{array}$ \\
\hline Lemhöfer et al. (2008) & $\begin{array}{l}\text { Progressive demasking } \\
\text { identification }\end{array}$ & 1,025 English words & $\begin{array}{l}20 \text { native speakers, and three groups of } \\
\text { bilinguals with English as L2 }\end{array}$ \\
\hline Ferrand et al. (2010) & Lexical decision & 38,840 French words & 975 students \\
\hline $\begin{array}{l}\text { Keuleers, Diependaele, \& } \\
\text { Brysbaert (2010) }\end{array}$ & Lexical decision & $\begin{array}{l}\text { 14,037 Dutch monosyllabic and } \\
\text { disyllabic words }\end{array}$ & 39 students and university personnel \\
\hline
\end{tabular}

al. (2007) differs from those by Ferrand et al. (2010) and Keuleers, Diependaele, \& Brysbaert (2010) in language (English vs. French and Dutch), stimulus presentation (uppercase vs. lowercase), and type of nonwords used (manual vs. statistical construction). Keuleers, Diependaele, and Brysbaert's study additionally differs from the other studies in experiment design and duration. As long as data analysis of the different studies yields comparable results, one can confidently conclude that the differences are irrelevant for the topic being studied. However, when there are discrepancies between the results, it becomes nearly impossible to trace their origin.

To fill the gap between the various databases, we ran a new megastudy in English, using the design of Keuleers, Diependaele, \& Brysbaert (2010). By comparing the new data with those in the existing studies in English, we can investigate to what extent the results depend on procedural choices, and by comparing the new data with those already collected in Dutch, we can examine to what extent they depend on language. For convenience, we refer to the new study as the British Lexicon Project (BLP), in analogy with the English Lexicon Project (ELP; Balota et al., 2007), the French Lexicon Project (FLP; Ferrand et al., 2010), and the Dutch Lexicon Project (DLP; Keuleers, Diependaele, \& Brysbaert, 2010).

Since existing data sets often fall short in the number of low-frequency words they contain, we decided to use words with frequencies as low as 0.02 per million words (see below). As a result, over 28,000 words were included in the stimulus list (note that all words were mono- or disyllabic).

One of the goals in collecting the data for the BLP was to have an English data set that would allow for straightforward analysis on individual RTs, rather than on average RTs per item. While the ELP was designed primarily to allow analysis on item means, the BLP design follows the approach taken by Keuleers, Diependaele, \& Brysbaert (2010) and is better suited for analysis on individual RTs, using linear mixed effects models with crossed random effects for participants and items (Baayen, Davidson, \& Bates, 2008), eliminating the need for separate participant $\left(F_{1}\right)$ and item $\left(F_{2}\right)$ analyses. It is also possible to run this type of analysis on the ELP data, but, due to the lack of orthogonal variation, trial-level analyses are less powerful. We will come back to this point in the discussion.

\section{Method}

\section{Participants}

A total of 78 participants completed the experiment. They were students (both undergraduates and graduates) or employees of Royal Holloway, University of London. Participants were recruited via the university Web site and word of mouth. They were informed that successful completion of the experiment would take about $16 \mathrm{~h}$, for which they would receive a payment of $£ 200$. They were also informed that they had to attain a consistent accuracy level of $80 \%,{ }^{1}$ that their average RT should stay below $1 \mathrm{~s}$, and that all trials had to be completed. Participants were informed that if they failed to meet these targets, they would be excluded from further participation and would be paid $£ 5$ per hour completed.

In addition to the participants who successfully completed the experiment, 27 more participants did not continue to the end, either because they did not return after

\footnotetext{
${ }^{1}$ In Keuleers, Diependaele, \& Brysbaert (2010), the accuracy level was set at $85 \%$. However, given the high number of very low-frequency words in the present study, this accuracy level was not thought realistic here.
} 
the first few sessions (13) or because their performance level was consistently below $80 \%$ correct (14).

\section{Stimuli}

To select the word stimuli, we used two sources. The first source, of which all words were included in the study, was a list of 8,010 monosyllabic words with a minimal length of two letters used in the DRC model of visual word recognition (Coltheart, Rastle, Perry, Langdon, \& Ziegler, 2001). The second source consisted of 22,725 disyllabic words with a total frequency of at least 2 in the British National Corpus (BNC, available at http://www.natcorp.ox.ac.uk). ${ }^{2}$ Since the BNC corpus contains 100 million words, the lower frequency bound was 0.02 words per million. The list was cleared of typing errors, acronyms, low-frequency names of people and places, and non-British English spellings, leaving us with a total of 20,720 disyllabic words.

Because it takes over $32 \mathrm{~h}$ to make lexical decisions to 28,700 words and the same number of nonwords, a random permutation of the list was split in two. One half was given to the participants with odd ranks; the other half was given to the participants with even ranks. Because the dropout was not the same in both groups, we ended up with 40 participants in the list with odd ranks, against 38 participants in the list with even ranks.

Nonwords were generated using Wuggy, a multilingual pseudoword generator (Keuleers \& Brysbaert, 2010). For a given target word, the Wuggy algorithm generates the best corresponding nonword, given a number of criteria. For the present experiment, we used the following criteria: (1) The nonword matched the syllabic and subsyllabic structure of the target word; (2) it differed from the target word in exactly one subsyllabic segment (onset, nucleus, or coda) for monosyllabic target words and in two subsyllabic segments for disyllabic target words; (3) the transition frequencies of the subsyllabic segments of the target word were matched as closely as possible; and (4) the morphological structure of the word was retained (e.g., if the word was a plural form, we tried to make a matching pseudoplural). Nonwords were created independently for each word list, meaning that there was a small overlap. As a result, while each participant saw a particular nonword only once, some nonwords were presented to all 78 participants. Most nonwords, however, were used in only one stimulus list and, therefore, were responded to by either 40 or 38 participants.

\section{Procedure}

The experiment started with an intake session, in which participants received information about the experiment and

\footnotetext{
${ }^{2}$ This list was kindly provided to us by James Adelman.
}

completed a questionnaire about their reading behavior and knowledge of other languages. Participants then completed a practice session of 200 trials using trisyllabic words and matching nonwords, allowing us to demonstrate the main features of the experiment. Responses were collected using a response box connected to the USB port. Participants used their dominant hand for word responses and their nondominant hand for nonword responses.

The experiment consisted of 57 test blocks of 500 trials and a final block of 230 trials. A trial consisted of the following sequence of events. First, two vertical fixation lines appeared slightly above and below the center of the screen, with a gap between them wide enough to clearly present a horizontal string of letters. Then participants were asked to fixate on the gap as soon as the lines appeared. A stimulus was presented $500 \mathrm{~ms}$ later in the gap between the vertical lines, which stayed on-screen. Following the response, the screen was blanked for $500 \mathrm{~ms}$, after which the next trial started. We did not impose a time limit for responses, thus allowing us to collect very long RTs and limiting the loss of data from trials due to inattention.

After every 100 trials (about $3 \mathrm{~min}$ ), a pause-screen was presented that gave participants information about their progress in the block and gave them the opportunity to take a short break if needed. After each block of 500 trials, participants received feedback about the percentage of correct trials for that block.

After the intake session, participants were free to organize their subsequent sessions by signing up for available time slots. Five experimental computers were used in parallel, and participants could choose to sit at any available computer. After entering a registration code, they were presented with a screen displaying their name and the number of their last completed block. After the participant confirmed this information, the next block started. Every evening, data were copied to a central computer, which automatically generated a review sheet, allowing the experimenters to verify participants' progress and performance. Display and timing routines for the experiment were programmed in C using the Tscope library (Stevens, Lammertyn, Verbruggen, \& Vandierendonck, 2006).

\section{Results}

The results section starts with a general overview of the data. Unless indicated otherwise, analyses are limited to word trials.

\section{Descriptive statistics}

For each word, three dependent variables were defined: (1) the percentage of correct responses, or accuracy, calculated 
on all 38 or 40 participants; (2) the mean RT of the correct word responses; and (3) the mean standardized RT ( $z \mathrm{RT})$ of the correct word responses, calculated on the $z$-scores of the word RTs per participant and per block. Before computing mean RTs and $z$ RTs, $2.3 \%$ of outliers were removed. Outliers were defined per participant and block, using a method commonly applied for box plots: First the interquartile distance (the distance between quartile 1 and quartile 3) was computed; RTs were then defined as outliers when they were higher than 3 interquartile distances above quartile 3 or lower than 3 interquartile distances below quartile 1 . Since there were no time limits for responses in our study, this method, which is robust to the influence of extreme outliers, is particulary suitable. Of course, other researchers are invited to use their own choice of trimming method on the raw data.

Table 2 lists the summary statistics of the items. For comparison purposes, the statistics of the mono-and disyllabic words of the ELP and the DLP are included as well. From this table, the similarities between the BLP and the DLP are clear. The main differences are the higher error rates to the words and the lower RTs to the nonwords in the BLP. The main reason for this, arguably, is that the BLP included more very low frequency words, which the participants experienced as nonwords. In both the BLP and the DLP, participants' responses to words were $80 \mathrm{~ms}$ faster, on average, than in the ELP (the RTs of which, in general, are longer than in published studies; see below).

\section{Practice effects}

Figure 1 displays the effect of practice by plotting the average accuracy and RT over blocks. For RT, the effect is on the order of $100 \mathrm{~ms}$ on the word trials, which is larger than the effect observed in the DLP (where it was $40 \mathrm{~ms}$ ). In addition, participants' response pattern to words and nonwords seems to have shifted during the experiment. Whereas the beginning of the experiment showed the usual pattern of longer RTs to nonwords than to words, around block 16 responses to nonwords became faster than responses to words. In our opinion, this is because a reasonably large number of words (up to $25 \%$ ) were perceived as nonwords, so that participants had the impression that the experiment contained more nonword trials than word trials and adapted their response bias accordingly. In this respect, a study by Wagenmakers, Ratcliff, Gomez, and McKoon (2008, Experiment 2) may be particularly informative. These authors showed that in a lexical decision task with $25 \%$ nonwords and $75 \%$ words, responses to words were faster than responses to nonwords, whereas in a task with $75 \%$ nonwords and $25 \%$ words, the difference was reversed, with a similar effect for error rates. Interestingly, the word frequency effect remained the same:
$103 \mathrm{~ms}$ in the $25 \%$ nonword condition versus $109 \mathrm{~ms}$ in the $75 \%$ nonword condition. By means of analyses with the diffusion model, Wagenmakers et al. showed that while the percentage of nonword trials did not change wordprocessing latencies, it altered the participants' response criteria. In terms of the diffusion model, it affected the starting point of the diffusion process and the separation between the decision criteria.

While the practice effect in our study has an intrinsic interest, researchers interested purely in word processing may prefer to partial out the effect. An easy way to do this is to use the normalized RTs ( $z$ RTs), which have a mean of 0 per block. Alternatively, time-specific variables, such as block number, can be entered as covariates in the statistical analysis.

Reliability of the dependent variables

The simplest way to determine the reliability of a variable is to calculate the split-half correlation and attenuate it for length, a method that has been applied for the FLP (Ferrand et al., 2010) and DLP (Keuleers, Diependaele, \& Brysbaert 2010). Using this method, the reliability of the BLP word responses is .72 for RT (there is a difference of less than .01 between the odd and the even groups, due to larger number of participants in the former), .81 for $z \mathrm{RT}$, and .96 for accuracy. These values are very similar to those obtained in DLP. The most likely explanation for the increased reliability of $z \mathrm{RT}$, as compared with $\mathrm{RT}$, is that the $z \mathrm{RTs}$ are less sensitive to the effects of practice.

Since lexical decision experiments usually have a rather high number of missing data (due to the errors made), Courrieu, Brand-D'Abrescia, Peereman, Spieler, and Rey (2011) proposed evaluating reliability using intraclass correlation (ICC), a method that is less sensitive to missing data. With the method described by Courrieu et al., a reliability of .82 was obtained for RT. For $z$ RT it was .87 , and for accuracy .96 (reliabilities were nearly equivalent for the odd and even groups of participants). ${ }^{3}$ In line with Courrieu et al.'s analysis, the ICC reliabilities are higher for $\mathrm{RT}$ and $z \mathrm{RT}$, but not for accuracy (where there were no missing data). Courrieu et al. also proposed the Expected Correlation Validation Test (ECVT) to test whether the ICC method is valid for a given data set by comparing the expected and observed ICCs for different numbers of participants. When applied to our data, the expected and observed correlations were indistinguishable. Figure 2 shows the results of the ECVT for $z$ RTs for the odd group of participants. Similar results were obtained for the even group and for RTs.

\footnotetext{
${ }^{3}$ The authors thank Pierre Courrieu for kindly agreeing to run the analyses and the Expected Correlation Validation tests.
} 
Table 2 Comparison of the British Lexicon Project (BLP) with the Dutch Lexicon Project (DLP) and the monosyllabic and disyllabic words of the English Lexicon Project (ELP)

\begin{tabular}{llll}
\hline & BLP & DLP & ELP (mono + di) \\
\hline Number of words & 28,730 & 14,034 & 22,143 \\
Length (characters) & $6.5(2-13)$ & $6.3(2-12)$ & $6.5(1-13)$ \\
Length (syllables) $_{\text {SUBTLEX frequency }}^{\mathrm{a}}$ & $1.7(1-2)$ & $1.8(1-2)$ & $1.7(1-2)$ \\
Accuracy words & $31.5(.02-41,857)$ & $59.7(0.02-39,883)$ & $42.6(0.02-41,857)$ \\
RT words & $77 \%(0-100)$ & $84 \%(0-100)$ & $85 \%(0-100)$ \\
Accuracy nonwords & $654(300-1,617)$ & $654(312-1382)$ & $730(415-1,589)$ \\
RT nonwords & $94 \%(0-100)$ & $94 \%(2-100)$ & $88 \%{ }^{\mathrm{b}}$ \\
\hline
\end{tabular}

${ }^{a}$ SUBTLEX frequencies refer to word form frequencies calculated on a corpus of 40-50 million words from film and television subtitles. Frequencies are expressed as frequency per million words. English frequencies are from Brysbaert and New (2009); Dutch frequencies are from Keuleers, Brysbaert, and New (2010). For the BLP words, there were SUBTLEX frequencies for only 25,316 words, partly because of spelling differences between British and American English. Therefore, unless indicated otherwise, for the analyses reported in this article, we used the $\mathrm{BNC}$ frequencies, which had an average of 26.9 per million and ranged from 0.01 to 61,879 per million.

${ }^{\mathrm{b}}$ Based on the full ELP

\section{Correlations between the BLP and ELP}

The most straightforward way to compare the BLP with the ELP is to correlate the various dependent variables. There were 18,969 words in common between the BLP and ELP. ${ }^{4}$ In order to interpret the intercorrelations shown in Table 3, it is useful to know that the reliability as calculated above gives an estimate of how much a variable would correlate with itself if the study were repeated. The reliability of .81 for $z \mathrm{RT}$ means that one can expect a correlation of .81 between $z \mathrm{RT}$ and the $z$ RT calculated on a new, similar study. If we look at the obtained correlations, we see that the correlations for standardized RTs $(r=.77)$ and for accuracy scores $(r=.79)$ approach these ceiling levels. The correlation for $z$ RTs remains high even when the data are limited to those words that are known to two thirds of the participants in both the British and the American studies $(r=.73, N=15,241)$.

Table 4 gives the 40 words with the highest residuals when the ELP $z$ RTs are regressed on the BLP $z$ RTs, for words that were known by at least two thirds of both groups of participants. Apart from some typical British and American words, we see that the ELP participants were faster on names, possibly because, in the ELP, words were presented in capitals (HOMER), whereas in the BLP, they were presented in lowercase letters (homer).

Correlation with the Balota, Cortese, Sergent-Marshall, Spieler, and Yap (2004) data

Balota et al. (2004) collected lexical decision times for 2,906 monosyllabic words from a group of young adults

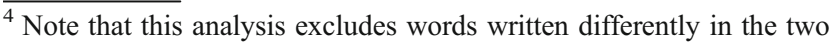
databases (e.g., labor vs. labour).
}

very similar to the participants for the BLP. Table 5 lists the correlations between the BLP and the Balota et al. (2004) data. The two studies had 2,328 words in common. Despite the smaller range of some variables (e.g., fewer very low frequency items in this database, all words monosyllabic), the correlations range between .6 and .7 .

In addition to examining correlations between similar variables, it is interesting to correlate RTs and accuracies with some of the major predictors of lexical decision performance: word length, word frequency (SUBTLEX; Brysbaert \& New, 2009), age of acquisition (AoA), word familiarity, and imageability. These correlations, based on measurements collected by Cortese and Khanna (2007, 2008) are listed in Table 6 and clearly show the overwhelming similarity between the Balota et al. (2004) lexical decision data set and the BLP data.

Figure 3 shows the frequency effect in the BLP and ELP for the words present in both databases. Stimuli were binned in groups of 1,000, and the means are given. The figure also shows the standard deviation of the RTs in each bin.

In Fig. 3, we see that the frequency effect is very similar for the BLP and ELP but that RTs were up to $100 \mathrm{~ms}$ shorter in the BLP than in the ELP. Also, the standard deviations of the RTs were larger in the ELP than in the BLP. In Fig. 4, the same data are plotted using standardized RTs, showing that for this variable, the frequency effect is more pronounced in the BLP than in the ELP. When interpreting these data, it is important to keep in mind that the ELP $z$ RTs were calculated on all $40 \mathrm{~K}$ words present in that database, including the long words of more than two syllables. As a result the $z$ RTs of the monosyllabic and disyllabic words in the ELP are lower than those in the BLP.

Finally, Fig. 5 shows the effect of word frequency on accuracy. Here, too, the effect is more pronounced for the 

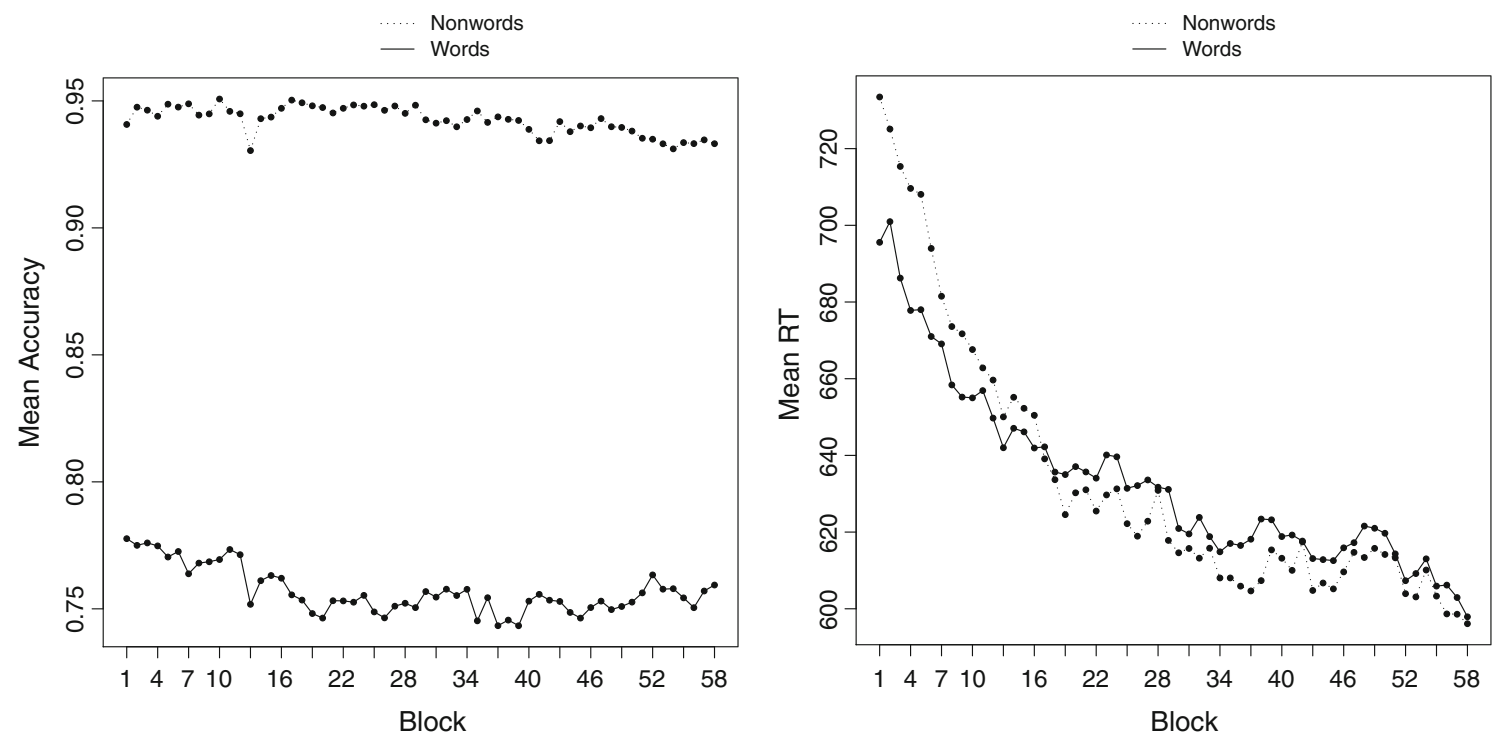

Fig. 1 The effects of practice on accuracy (left panel) and response latency (right panel)

BLP - in particular, at the very low frequency end (below 0.5 per million).

\section{Virtual experiments}

The BLP approach, in which two groups of participants each see half of the stimuli, allows for straightforward generalization across stimuli and across participants. Therefore, we can run virtual experiments by extracting the relevant information from the full database (containing the data of the individual

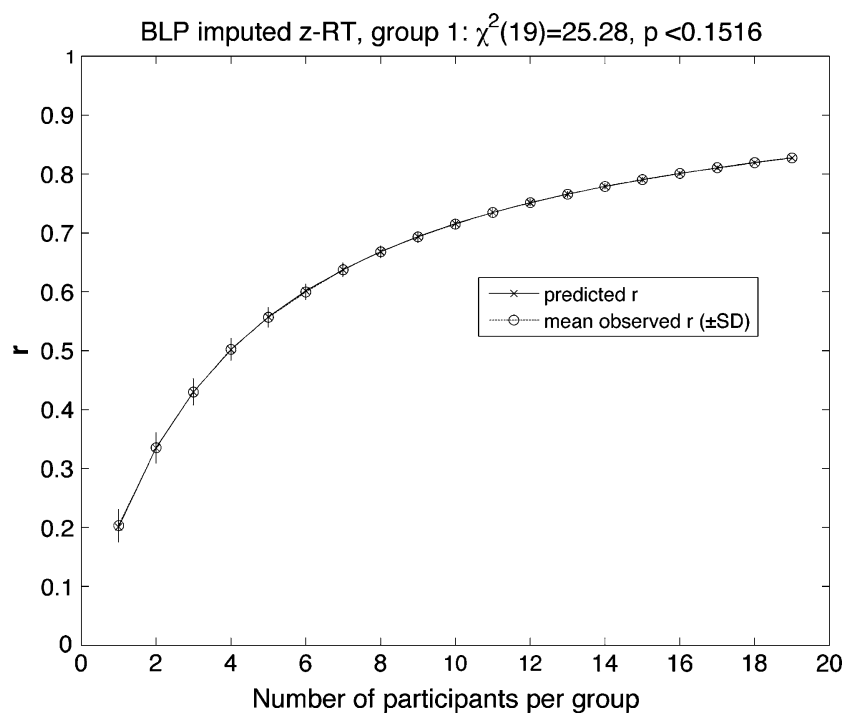

Fig. 2 ECVT test (Courrieu et al., 2011) on $z$ RTs data of Group 1 $(n=38)$, after imputation of $26 \%$ missing data by the CRARI algorithm (Courrieu \& Rey, 2011). The "predicted" and "observed" curves are indistinguishable, and the $\chi^{2}$ test does not detect a significant difference between them. Therefore, the ICC method can be considered valid for these data participants) and running a linear mixed effects analysis (see also Keuleers, Diependaele, \& Brysbaert 2010).

Below, we compare some classical findings in English word recognition research with those for virtual experiments, using the BLP data.

Word frequency As was shown above, there is a healthy frequency effect in the full BLP data. In Table 7, we examine how the RT effects of frequency from some classical studies compare with effects found using virtual experiments involving the same items from the BLP.

Table 7 illustrates that the frequency effect in the BLP is similar to that of published experiments. As will become clear below, this is true only for experiments with short RTs. In experiments with longer RTs, the frequency effect tends to be more pronounced than in the BLP. An interesting study in this context was published by Yap, Balota, Tse, and Besner (2008, Experiments 2-4). They examined the size of the frequency effect as a function of vocabulary size, by comparing the results of three universities with different student populations. ${ }^{5}$ As can be seen in Table 8, larger vocabulary sizes corresponded with shorter RTs and smaller frequency effects. Therefore, the most likely explanation for the short RTs and the relatively small size of the frequency effect is that the participants we tested, on average, had a large vocabulary size, which seems plausible given the nature of our experiment and the fact that we required them to have an accuracy level above $80 \%$.

In a similar vein to Yap et al. (2008), Chateau and Jared (2000) provided evidence that the frequency effect is

\footnotetext{
${ }^{5}$ Because the nonwords used in these studies were pseudohomophones (e.g., brane, which sounds like the existing word brain), they were not included in Table 7.
} 
Table 3 Correlations between the word data of the British Lexicon Project (BLP) and English Lexicon Project (ELP; lexical decision)

\begin{tabular}{lllccc}
\hline & BLPzrt & BLPacc & ELPrt & ELPzrt & ELPacc \\
\hline BLPrt & .954 & -.685 & .679 & .730 & -.588 \\
BLPzrt & & -.767 & .710 & .770 & -.656 \\
BLPacc & & & -.580 & -.653 & .788 \\
ELPrt & & & & .937 & -.595 \\
ELPzrt & & & & & -.690 \\
\hline
\end{tabular}

All correlations are significant at the .0001 level $(N=18,969)$

mediated by print exposure, as measured with a reading test and an author recognition test. In their experiment, the high print exposure group showed a frequency effect of $128 \mathrm{~ms}$ (537 vs. $665 \mathrm{~ms}$ ), whereas the low-exposure group had a frequency effect of $278 \mathrm{~ms}$ ( $618 \mathrm{vs} .896 \mathrm{~ms})$. Interested in seeing whether the effect found by Chateau and Jared's (2000) experiment was caused by their use of pseudohomophones as nonwords, Sears, Siakaluk, Chow, and Buchanan (2008) compared a condition using pseudohomophonic nonwords with a condition using typical pseudowords (e.g., brint). Whereas the difference in the frequency effect between print exposure groups was found using

Table 4 Words with the largest residual difference in $z$ RT between the British Lexicon Project (BLP) and English Lexicon Project (ELP)

\begin{tabular}{ll}
\hline BLP Much Faster & BLP Much Slower \\
\hline nightie & homer \\
greaseproof & lincoln \\
offence & boston \\
postcode & johnny \\
catchphrase & mom \\
sulphate & speedway \\
oxtail & sears \\
wholemeal & roger \\
levelled & softball \\
signposts & plato \\
gasworks & lawless \\
ferries & farthest \\
heartstrings & ralph \\
instructs & butts \\
transience & wick \\
tongs & dean \\
strengthens & heather \\
defence & peter \\
yachtsman & singed \\
drainpipe & babes \\
moulding & tooling \\
\hline
\end{tabular}

Table 5 Correlations between the word data in the BLP and Balota et al. (2004), young adults;[B04])

\begin{tabular}{lllcl}
\hline & BLP zRT & BLP Accuracy & B04 RT & B04 Accuracy \\
\hline BLPrt & \multirow{2}{*}{.968} & -.682 & .693 & -.589 \\
BLPzrt & & -.728 & .716 & -.616 \\
BLPacc & & & -.589 & .612 \\
BAL04rt & & & & -.589 \\
\hline
\end{tabular}

All correlations are significant at the .0001 level $(N=2,328)$.

pseudohomophonic nonwords, the interaction between print exposure and the frequency effect was not present in the experiment with legal nonwords. However, the participants in Sears et al. (2008) were fast readers with small frequency effects, overall, in line with those for the BLP participants. We will return to the Chateau and Jared (2000) and Sears et al. (2008) studies below when we discuss the effect of orthographic neighborhood size (Table 11).

Table 7 further shows that the interaction between frequency and animacy found by Monsell, Doyle, and Haggard (1989) was not present in the BLP data. This is interesting, because Monsell et al. did not expect to find this interaction effect. As they wrote, "For unknown reasons, possibly to do with our selection of items, the frequency effect was significantly weaker for the thing nouns than for the person nouns" (p. 55). The BLP data show that the unexpected interaction indeed cannot be replicated using megastudy data, in which participants respond to a large numbers of words and nonwords. On the other hand, we did obtain a significant interaction between frequency and the stressed syllable position (note the same trend in the data in Monsell et al., 1989). Why the frequency effect is smaller in the words with final stress, which as a group are less common than words with initial stress, is at present not clear.

Table 6 Correlations between word characteristics and average RTs and accuracies for Balota et al. (2004), young adults; [B04]). and the British Lexicon Project (BLP; words for which all data are available; $N=2,328)$

\begin{tabular}{llllll}
\hline & \multicolumn{2}{l}{$\mathrm{RT}$} & & \multicolumn{2}{l}{ Accuracy } \\
\cline { 2 - 3 } \cline { 5 - 6 } & $\mathrm{B} 04$ & $\mathrm{BLP}$ & & $\mathrm{B} 04$ & $\mathrm{BLP}$ \\
\hline Length & $.092^{* *}$ & $.147^{* *}$ & & .022 & .039 \\
Frequency & $-.598^{* *}$ & $-.617^{* *}$ & & $.414^{* *}$ & $.456^{* *}$ \\
AoA & $.649^{* *}$ & $.645^{* *}$ & & $-.501^{* *}$ & $-.500^{* *}$ \\
Familiarity & $-.605^{* *}$ & $-.608^{* *}$ & & $.445^{* *}$ & $.454^{* *}$ \\
Imageability & $-.274^{* *}$ & $-.273^{* *}$ & & $.303^{* *}$ & $.266^{* *}$ \\
\hline
\end{tabular}

AoA, age of acquisition.

$* * p<.01$ 


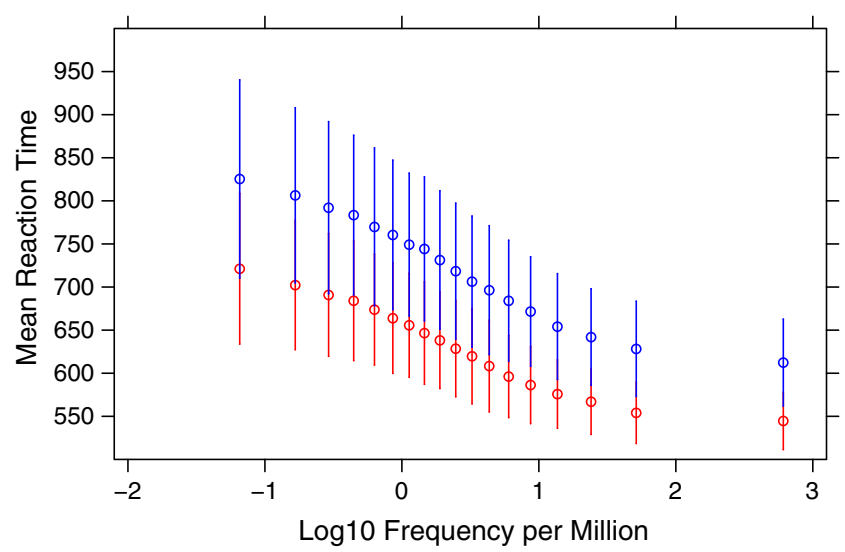

Fig. 3 The frequency effect in the English Lexicon Project (blue lines) and the British Lexicon Project (red lines). Stimuli were binned by frequency in groups of 1,000. Each line shows the mean RT and the standard deviation for a bin. Frequencies were based on British National Corpus. $\log 10$ frequency is the $\log 10$ of the frequency per million (i.e., for 0.1 per million, its value is -1.0)

Age of acquisition It has repeatedly been claimed that early-acquired words are processed faster than late acquired words, independently of word frequency. As Table 9 illustrates, the BLP data show the same results, and the size of the age-of-acquisition effect is the same as that reported in published experiments, even when the latter had longer RTs.

Regular versus irregular words An important topic in visual word recognition is the interaction between word frequency and the consistency of the letter-sound mappings. It is well established that in word naming, the cost of an irregular or inconsistent mapping is higher for low-frequency words than for high-frequency words (Seidenberg, Waters, Barnes, \& Tanenhaus, 1984). There

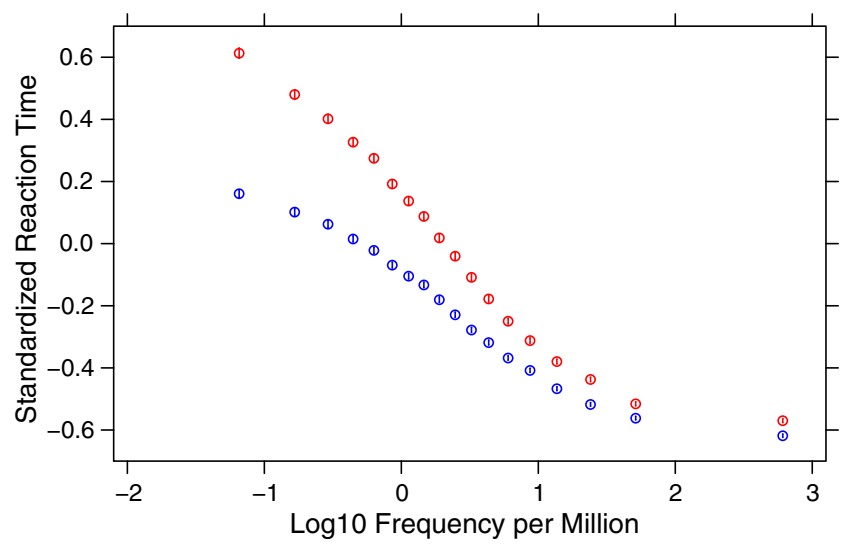

Fig. 4 The word frequency effect in the English Lexicon Project (blue) and the British Lexicon Peojct (red) when expressed in standardized reaction times. The whiskers represent standard errors

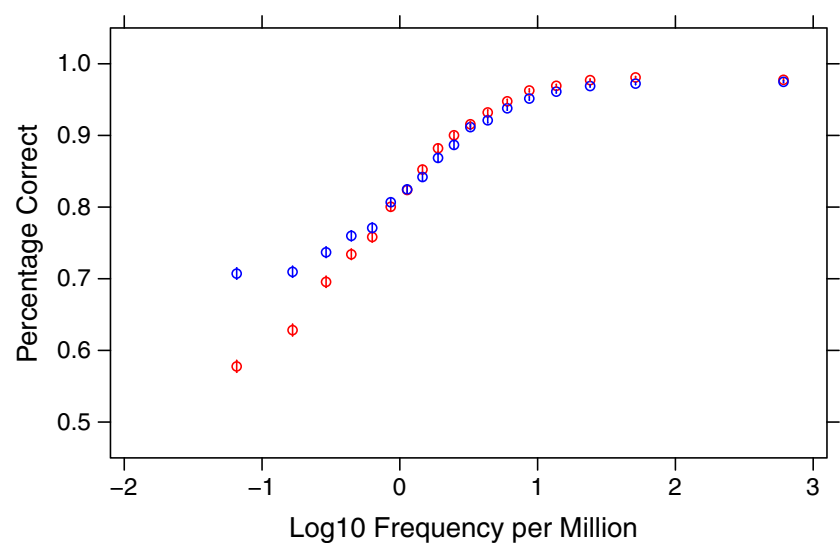

Fig. 5 The word frequency effect on accuracy in the English Lexicon Project (blue) and British Lexicon Project (red)

is more discussion about whether the same interaction exists for lexical decision times, with the "classical" studies giving null effects. Table 10 summarizes the findings. As can be seen, the expected interaction does not show up in the BLP data. For the stimuli of Hino and Lupker (1996), the regularity effect even seems to be the reverse of the expected one. The only effect that was replicable is that of feedback inconsistency reported by Stone, Vanhoy, and Van Orden (1997, Experiment 2): Participants needed more time to accept a word that is feedback inconsistent, meaning that its pronunciation body can be spelled in more than one way (for instance, the rime of a syllable with the sound /ip/ can be spelled -eep, as in deep or -eap, as in heap). Interestingly, this was the case only for spelling patterns that are feedforward consistent, meaning that they are unambiguous in their pronunciation (e.g.,--eap is always pronounced /ip/, while -eat is pronounced differently in sweat and in heat). Surprisingly, the feedback consistency effect reported by Stone et al. (1997, Experiment 1) was not found with the BLP virtual experiment.

Neighborhood size Another important topic in word recognition research is the way in which a word's recognition is affected by its orthographic neighbors - that is, the words that differ from the target word in one letter at one position. When a person sees the input word lost, its orthographic neighbors most, list, loft, and lose are thought to become activated as well and to compete with the target word in the word recognition process. Andrews (1992) found that words with a large neighborhood size $(N)$ were responded to more quickly in lexical decision than were words with a small $N$-in particular, if they were low-frequency words. This finding was unexpected given that neighbors were assumed to compete with each other and, thus, to have inhibitory effects (Segui \& Grainger, 1990). A possible 
Table 7 Published lexical decision experiments involving frequency effects and virtual experiments with the same stimuli from the British Lexicon Project (studies are chronologically ordered)

\begin{tabular}{|c|c|c|c|}
\hline & & Original Experiment RTs & Virtual Experiment RTs \\
\hline \multirow[t]{9}{*}{ Monsell, Doyle, and Haggard (1989, Experiment 1) } & High frequency, person & 538 & 535 \\
\hline & High frequency, thing & 541 & 539 \\
\hline & Medium frequency, person & 553 & 570 \\
\hline & Medium frequency, thing & 570 & 565 \\
\hline & Low frequency, person & 639 & 640 \\
\hline & Low frequency, thing & 617 & 618 \\
\hline & Effect of frequency & $88^{* *}$ & $92 * *$ \\
\hline & Effect of animacy & 1 & 8 \\
\hline & Frequency $\times$ animacy interaction & $p<.01$ & n.s. \\
\hline \multirow[t]{7}{*}{ Monsell et al. (1989, Experiment 3) } & High frequency, initial stress & 538 & 541 \\
\hline & High frequency, final stress & 543 & 551 \\
\hline & Low frequency, initial stress & 642 & 646 \\
\hline & Low frequency, final stress & 616 & 598 \\
\hline & Effect of frequency & $89^{* *}$ & $77 * *$ \\
\hline & Effect of stress & 10 & $19^{+}$ \\
\hline & Frequency $\times$ stress Interaction & 15 & $29 * *$ \\
\hline \multirow[t]{3}{*}{ Morrison and Ellis (1995, Experiment 6) } & High frequency & 548 & 542 \\
\hline & Low frequency & 602 & 576 \\
\hline & Effect of frequency & $54 * *$ & $34 * *$ \\
\hline \multirow[t]{3}{*}{ Yap et al. (2008, Experiment 1) } & High frequency & 557 & 531 \\
\hline & Low frequency & 605 & 574 \\
\hline & Effect of frequency & $48 * *$ & $43 * *$ \\
\hline
\end{tabular}

$* * p<.01, * p<.05,{ }^{+} p<.10$ or significant only in $F_{1}$ or $F_{2}$

explanation of this unexpected finding was that words with many neighbors look more wordlike than do words with few neighbors and elicit a word response on the basis of the general activation in the lexicon, rather than on the basis of recognition of the precise target word (Grainger \& Jacobs, 1996).

Table 11 lists the most important studies on the topic, together with the results of the virtual experiments. From this table, we can conclude that, overall, the BLP data do not show significant effects of neighborhood size. At the same time, the original studies on the neighborhood size effect showed considerably stronger frequency effects than did the virtual experiments, not all of which can be explained by differences in overall RTs. This may indicate that lexical decision experiments including only words with extreme values of a particular dimension (high vs. low frequency, many vs. few neighbors) tend to exaggerate the importance of this dimension, relative to studies including words from the entire continuum.

Yates and colleagues (Yates, 2005, 2009; Yates, Locker, \& Simpson, 2004) suggested that a word's phonological neighbors are more important than its orthographic neighbors. Table 12 shows the results of the various experiments run by Yates and colleagues, together with the simulations. Contrary to the orthographic neighborhood data, the phonological neighborhood data were observed mostly in the virtual experiments, although, again, the effects tended to be smaller than in the original studies. Only the most

Table 8 Data from Yap et al. (2008), illustrating the frequency effect as a function of the vocabulary size

\begin{tabular}{|c|c|c|c|c|c|c|}
\hline University & Age & Years of Education & Vocabulary Age & $\mathrm{RT}_{\mathrm{HF}}$ & $\mathrm{RT}_{\mathrm{LF}}$ & Effect \\
\hline Washington University & 20.9 & 13.8 & 18.7 & 612 & 678 & 66 \\
\hline University of Waterloo & 20.9 & NA & 17.7 & 658 & 753 & 95 \\
\hline University at Albany (SUNY) & 19.4 & 12.2 & 16.9 & 732 & 844 & 112 \\
\hline
\end{tabular}


Table 9 Age of acquisition (AoA) effects in published lexical decision experiments and in virtual experiments with the same stimuli as those from the British Lexicon Project

\begin{tabular}{llll}
\hline & & Original Experiment RTs & Virtual Experiment RTs \\
\hline Morrison and Ellis (1995, Experiment 5) & Early acquired & 582 & 552 \\
& Late acquired & 648 & 604 \\
& Effect of AoA & $66^{* *}$ & $52^{* *}$ \\
Gerhand and Barry (1998, Experiment 1) & Early acquired, high frequency & 593 & 540 \\
& Early acquired, low frequency & 621 & 538 \\
& Late acquired, high frequency & 603 & 584 \\
& Late acquired, low frequency & 730 & 623 \\
& Effect of AoA & $59^{* *}$ & $65^{* *}$ \\
& Effect of frequency & $77^{* *}$ & $20^{+}$ \\
& Frequency $\times$AoA Interaction & $50^{* *}$ & \\
\hline
\end{tabular}

$* * p<.01, * p<.05,{ }^{+} p<.10$ or significant only in $F_{1}$ or $F_{2}$

recent study (Yates, 2009), comparing the lexical decision times to monosyllabic words with neighbors for all three subsyllabic segments $(P=3)$ with those to words with neighbors for just two subsyllabic segments $(P=2)$, did not reach significance in the virtual experiment.

Bigram frequency The frequency of a word's letter bigrams is often considered to affect word recognition and is, therefore, often controlled for in experiments. Surprisingly, in the only study we could find on this variable (Andrews, 1992, Experiment 3), words with familiar bigrams were not responded to faster than words with rare bigrams. The same pattern is observed in the BLP (Table 13).

Polysemy The final topic we will address is the effect of polysemy - that is, the existence of different meanings for the same word. As can be seen from Table 14, word recognition research has suggested a small facilitation effect of number of meanings. Although there is a similar tendency in the BLP, none of the effects reached significance in the virtual experiments.

Rodd, Gaskell, and Marslen-Wilson (2000) criticized the existing research on polysemy in word recognition because it failed to make a distinction between words with multiple related senses (e.g., the adjective uniform [similar in form] and the noun uniform [clothing worn by a particular group]) and words with multiple unrelated meanings (e.g., bank [financial institution] and bank [land alongside a river]). Rodd et al.'s results suggested that the effect of polysemy was limited to words with true polysemy (multiple related senses). As Table 15 shows, the same tendency is found in the BLP data, but the effects are again smaller than in the original experiment. In addition, the BLP data suggest that both number of meanings and number of senses impact word recognition.

\section{Discussion}

We started our analysis of the BLP data by documenting the high correlation between the BLP and the ELP data. As a matter of fact, the correlation between the two data sets is close to the maximum that can be expected given the reliability of the scores in the individual databases, meaning that the methodological differences do not entail divergent results. This is useful for researchers who want to run new megastudies (e.g., in other languages).

The high correlation between the BLP and ELP is of further interest because it addresses an issue raised by Sibley, Kello, and Seidenberg (2009). These authors noted that word naming megastudies did not replicate the frequency $\times$ irregularity interaction found in small-scale factorial experiments and ventured that this was because megastudies contained too much noise to allow finegrained analyses. As long as there is only one major megastudy available in English, this criticism cannot be examined. However, now that we have the BLP and ELP, we can take a deeper look. If Sibley et al. are right and megastudies are characterized by a larger degree of noise (rather than other strategies used by participants when confronted with a random sample of words than with a sample of target words differing on one or two dimensions), the data of the two megastudies will not agree more with each other than with the findings of small-scale factorial experiments.

To illustrate the approach, let us have a look at the data of Stone et al. (1997) on the effects of feedforward and feedback spelling-sound consistency in lexical decision (Table 10). For these data, we observed that BLP failed to replicate the feedforward consistency effect but presented evidence in favor of the feedback consistency effect. If the null effect of feedforward consistency is due to poor power 
Table 10 The interaction between word frequency and spelling-sound consistency in published lexical decision experiments and in virtual experiments with the same stimuli as those from the British Lexicon Project

\begin{tabular}{|c|c|c|c|}
\hline & & Original Experiment RTs & Virtual Experiment RTs \\
\hline \multirow[t]{9}{*}{ Seidenberg et al. (1984, Experiment 2) } & High frequency, regular inconsistent & 584 & 534 \\
\hline & High frequency, strange & 570 & 526 \\
\hline & High frequency, regular & 601 & 534 \\
\hline & Low frequency, regular inconsistent & 626 & 603 \\
\hline & Low frequency, strange & 673 & 613 \\
\hline & Low frequency, regular & 633 & 598 \\
\hline & Effect of frequency & $59 * *$ & $73 * *$ \\
\hline & Effect of regularity & n.s. & n.s. \\
\hline & Frequency $\times$ regularity interaction & $p<.05$ & n.s. \\
\hline \multirow[t]{7}{*}{ Seidenberg et al. (1984, Experiment 3) } & High frequency, regular & 533 & 534 \\
\hline & High frequency, exception & 530 & 564 \\
\hline & Low frequency, regular & 601 & 600 \\
\hline & Low frequency, exception & 604 & 593 \\
\hline & Effect of frequency & $71 * *$ & $47 * *$ \\
\hline & Effect of regularity & 0 & -11 \\
\hline & Frequency $\times$ regularity interaction & 3 & 18 \\
\hline \multirow[t]{7}{*}{ Hino and Lupker (1996, Experiment 5b) } & High frequency, regular & 500 & 543 \\
\hline & High frequency, exception & 492 & 521 \\
\hline & Low frequency, regular & 573 & 597 \\
\hline & Low frequency, exception & 579 & 571 \\
\hline & Effect of frequency & $80 * *$ & $52 * *$ \\
\hline & Effect of regularity & -1 & $-24 *$ \\
\hline & Frequency $\times$ regularity interaction & 7 & 2 \\
\hline \multirow[t]{3}{*}{ Stone et al. (1997), Experiment 1) } & Feedback consistent & 774 & 597 \\
\hline & Feedback inconsistent & 807 & 595 \\
\hline & Effect of feedback consistency & $33 *$ & -2 \\
\hline \multirow[t]{7}{*}{ Stone et al. (1997, Experiment 2) } & Feedforward consistent, feedback consistent & 732 & 574 \\
\hline & Feedforward consistent, feedback inconsistent & 778 & 620 \\
\hline & Feedforward inconsistent, feedback consistent & 780 & 593 \\
\hline & Feedforward inconsistent, feedback inconsistent & 770 & 604 \\
\hline & Effect of feedforward consistency & $20^{+}$ & 2 \\
\hline & Effect of feedback consistency & $18^{+}$ & $29 * *$ \\
\hline & Feedforward $\times$ feedback interaction & $28^{+}$ & $18^{+}$ \\
\hline
\end{tabular}

$* * p<.01, * p<.05,{ }^{+} p<.10$ or significant only in $F_{1}$ or $F_{2}$

or to a peculiarity of the BLP, the ELP and BLP should not be more in agreement with each other than with the data of the original experiment. Table 16 shows the outcome of the analysis, and also when the analysis is based on the standardized scores (recall that these are less noisy). From this table, it is clear that the two megastudies are much more in agreement with each other than with the original study, thus adding extra weight to the megastudy findings.

The high correlation between the ELP and BLP indicates that a high percentage of variance in megastudies is systematic rather than noise (see also Rey \& Courrieu, 2010). Both databases can be used in combination to verify hypotheses, to cross-check a finding with one database on the other, or to train a mathematical model on one data set and to test it on the other, thereby avoiding the issue of overfitting. In this respect, the BLP design has an extra bonus because its design allows for more precise statistical analyses of the trial data than does the random sampling design used in the ELP (Keuleers, Diependaele, \& Brysbaert 2010; Rey \& Courrieu, 2010). To illustrate this, we performed a Monte Carlo simulation in which we took two random samples of words from the words occurring in both the BLP and the ELP at various sample sizes (between 10 and 160 words) and added a virtual effect (between 0 
Table 11 Studies addressing the effect of neighborhood size $(N)$ in published lexical decision experiments and in virtual experiments with the same stimuli from the British Lexicon Project

\begin{tabular}{|c|c|c|c|}
\hline & & Original Experiment RTs & Virtual Experiment RTs \\
\hline \multirow[t]{7}{*}{ Andrews (1992, Experiment 1) } & High frequency, small $N$ & 570 & 539 \\
\hline & High frequency, large $N$ & 586 & 535 \\
\hline & Low frequency, small $N$ & 757 & 642 \\
\hline & Low frequency, large $N$ & 714 & 625 \\
\hline & Effect of frequency & $157 * *$ & $96 * *$ \\
\hline & Effect of $N$ & -13 & -7 \\
\hline & Frequency $\times N$ interaction & $29 * *$ & 6 \\
\hline \multirow[t]{7}{*}{ Sears, Hino, and Lupker (1995, Experiment 1) } & High frequency, small $N$ & 528 & 532 \\
\hline & High frequency, large $N$ & 509 & 538 \\
\hline & Low frequency, small $N$ & 587 & 564 \\
\hline & Low frequency, large $N$ & 577 & 581 \\
\hline & Effect of frequency & $63 * *$ & $28 * *$ \\
\hline & Effect of $N$ & $15^{+}$ & $-12^{+}$ \\
\hline & Frequency $\times N$ interaction & 5 & 6 \\
\hline \multirow[t]{7}{*}{ Sears et al. (1995, Experiment 3) } & High frequency, small $N$ & 520 & 535 \\
\hline & High frequency, large $N$ & 518 & 546 \\
\hline & Low frequency, small $N$ & 669 & 595 \\
\hline & Low frequency, large $N$ & 617 & 587 \\
\hline & Effect of frequency & $124 * *$ & $50 * *$ \\
\hline & Effect of $N$ & $27^{+}$ & 1 \\
\hline & Frequency $\times N$ interaction & $25^{+}$ & 10 \\
\hline \multirow[t]{9}{*}{ Sears et al. (1995, Experiment 4a) } & Small $N$, no higher neighbors & 625 & 584 \\
\hline & Small $N, 1$ higher neighbors & 585 & 559 \\
\hline & Small $N$, many higher neighbors & 591 & 563 \\
\hline & Large $N$, no higher neighbors & 585 & 554 \\
\hline & Large $N, 1$ higher neighbors & 570 & 574 \\
\hline & Large $N$, many higher neighbors & 570 & 557 \\
\hline & Effect of $N$ & $25^{*}$ & 7 \\
\hline & Effect of higher neighbors & $27^{+}$ & 9 \\
\hline & $N \times$ neighbor level interaction & n.s. & $p=.11$ \\
\hline \multirow[t]{7}{*}{ Chateau and Jared $(2000)^{\mathrm{a}}$} & High frequency, small $N$ & 542 & 539 \\
\hline & High frequency, large $N$ & 533 & 535 \\
\hline & Low frequency, small $N$ & 694 & 642 \\
\hline & Low frequency, large $N$ & 636 & 625 \\
\hline & Effect of frequency & $127 * *$ & $96 * *$ \\
\hline & Effect of $N$ & $33 * *$ & -7 \\
\hline & Frequency x $N$ interaction & $24 * *$ & 6 \\
\hline \multirow[t]{7}{*}{ Sears et al. (2008, Experiment 1) } & High frequency, small $N$ & 520 & 532 \\
\hline & High frequency, large $N$ & 517 & 530 \\
\hline & Low frequency, small $N$ & 567 & 552 \\
\hline & Low frequency, large $N$ & 548 & 559 \\
\hline & Effect of frequency & $39 * *$ & $24 * *$ \\
\hline & Effect of $N$ & $11^{+}$ & -3 \\
\hline & Frequency $\times N$ interaction & $8^{+}$ & 4 \\
\hline
\end{tabular}

${ }^{a}$ Same stimuli as in Andrews (1992) but pseudohomophones as nonwords, only the high print exposure group. ${ }^{* *} p<.01,{ }^{*} p<.05,{ }^{+} p<.10$ or significant only in $F_{1}$ or $F_{2}$ 
Table 12 The effect of phonological neighborhood size in published lexical decision experiments and in virtual experiments with the same stimuli from BLP

\begin{tabular}{llll}
\hline & & Original Experiment RTs & Virtual Experiment RTs \\
\hline Yates et al. (2004, Experiment 1) & Small phonological neighborhood & 681 & 633 \\
& Large phonological neighborhood & 620 & 578 \\
& Effect of neighborhood & $61^{* *}$ & $55^{* *}$ \\
Yates et al. (2004, Experiment 2) & Small phonological neighborhood & 638 & 602 \\
& Large phonological neighborhood & 601 & 580 \\
& Effect of neighborhood & $37^{+}$ & 22 \\
Yates (2005) & Small phonological neighborhood & 729 & 610 \\
& Large phonological neighborhood & 656 & 567 \\
Yates (2009) & Effect of neighborhood & $73^{* *}$ & $43^{* *}$ \\
& $P=2$ & 647 & 575 \\
& $P=3$ & 620 & 566 \\
\hline
\end{tabular}

** $p<.01,{ }^{*} p<.05,{ }^{+} p<.10$ or only significant in $F_{1}$ or $F_{2}$

and $40 \mathrm{~ms}$ ) to the RTs of one group of items. For each combination of sample size and effect size, we ran 1,000 tests and noted how often the data showed a significant effect in an analysis on item means (a traditional $F_{2}$ ANOVA) and in a linear mixed effects model with crossed random effects for participants and items. The results are shown in Fig. 6 and confirm that larger sample sizes are required to find an effect in the ELP than in the BLP. For instance, in the item analysis, we can expect to find an effect of $40 \mathrm{~ms}$ with 40 items in the BLP, whereas a sample of about 70 items is required for the ELP. For the BLP, the results of the Monte Carlo simulations, using item analysis and mixed effects modeling, are nearly equivalent. For the ELP, however, the mixed effects model is less powerful than the item analysis, showing that, due to its design, the BLP is more suited to trial-level analysis than is the ELP.

Megastudies further allow researchers to reassess entire research traditions against a common framework. That is, each and every factorial experiment of which the original stimuli are known can be projected against the same set of megastudy data. This makes it possible to take away the peculiarities of the original studies and to directly compare results. The frequency effect provides a nice illustration.
Although the effect is clearly present in the megastudy data, it tends to be smaller in the BLP than in many of the original studies. Two factors seem to contribute to this pattern. First, participants with a large vocabulary and/or high reading exposure tend to be faster and to show a smaller frequency effect (Chateau \& Jared, 2000; Yap et al., 2008). Second, the frequency effect seems to be larger in small-scale factorial lexical decision experiments that include only low- and high-frequency words than in megastudies comprising all types of words. This finding raises the question as to what extent the use of two extreme categories exaggerates the effect under investigation, which we think is an important topic for future research, because our analyses suggest that a similar phenomenon may be responsible for the effects of orthographic neighborhood and spelling-sound consistency reported in some smallscale factorial studies.

Although virtual experiments are interesting, it must not be forgotten that the main strength of megastudy data is that they allow researchers to examine a continuous effect across the entire continuum. The frequency effect in Figs. 3 and 4 is a case in point. A cursory review of studies investigating the frequency effect suggests that, as a rule of
Table 13 Effects of frequency and bigram frequency in Andrews (1992, Experiment 3) and in a virtual experiment with the same stimuli as those in the British Lexicon Project

${ }^{* *} p<.01, * p<.05,{ }^{+} p<.10$ or significant only in $F_{1}$ or $F_{2}$

\begin{tabular}{lll}
\hline & Original Experiment RTs & Virtual Experiment RTs \\
\hline High word frequency, high bigram frequency & 592 & 532 \\
High word frequency, low bigram frequency & 594 & 531 \\
Low word frequency, high bigram frequency & 690 & 577 \\
Low word frequency, low bigram frequency & 686 & 591 \\
Effect of word frequency & $95^{* *}$ & $52^{* *}$ \\
Effect of bigram frequency & -1 & 6 \\
Word frequency $\times$ bigram frequency interaction & 3 & 7 \\
\hline
\end{tabular}


Table 14 Effects of polysemy on visual lexical decision times in published lexical decision experiments and in virtual experiments with the same stimuli as those in the British Lexicon Project

\begin{tabular}{llll}
\hline & & Original Experiment RTs & Virtual Experiment RTs \\
\hline Borowsky and Masson (1996, Experiment 3) & Polysemous & 637 & 555 \\
& Monosemous & 647 & 562 \\
& Effect of polysemy & $10^{+}$ & 7 \\
Hino and Lupker (1996, Experiment 1) & High frequency, polysemous & 548 & 524 \\
& High frequency, monosemous & 561 & 534 \\
& Low frequency, polysemous & 613 & 574 \\
& Low frequency, monosemous & 626 & 572 \\
& Effect of frequency & $65^{* *}$ & $44^{* *}$ \\
& Effect of polysemy & 4 \\
& Frequency $\times$ polysemy interaction & 0 & 6 \\
& High frequency, polysemous & 513 & 529 \\
& High frequency, monosemous & 511 & 531 \\
& Low frequency, polysemous & 567 & 564 \\
& Low frequency, monosemous & 609 & 570 \\
& Effect of frequency & $76^{* *}$ & $37^{* *}$ \\
& Effect of polysemy & $20^{*}$ & 22 \\
& Frequency $\times$ polysemy interaction & $22^{*}$ & \\
\hline
\end{tabular}

** $p<.01,{ }^{*} p<.05,{ }^{+} p<.10$ or significant only in $F_{1}$ or $F_{2}$

thumb, researchers choose their high-frequency words from frequencies above 50-100 per million, while low-frequency words have frequencies below $5-10$ per million. Looking at the frequency curve in megastudies (see also Keuleers, Diependaele, \& Brysbaert 2010), it becomes clear that there is virtually no frequency effect above 50 per million in the lexical decision task and that nearly half of the frequency effect is situated below 1-2 per million. The main reason why researchers have overlooked the importance of frequency differences below 1 per million may well be that nearly all research in English has been based on the Kučera and Francis measures, which are based on a corpus of only 1 million words (Brysbaert \& New, 2009).

It is our conviction that analyses across the entire continuum based on large numbers of data will be interesting for other variables as well. Each of the research topics we have raised above can be addressed by looking at the effect across the entire data set, rather than across the few handpicked words used in the original publications (see, e.g., Baayen \& Milin, in press, for an example). This considerably increases the power of the design (Keuleers, Diependaele, \& Brysbaert 2010). Furthermore, it allows researchers to go beyond merely determining the statistical significance of a variable. They can now see the curve of the entire effect and examine how strong the effect is in terms of explained variance.

\section{Availability}

The BLP data are available at the Web site http://crr.ugent. be/blp formatted as text, as Excel files, and as R data objects. In addition, we are making available a file of stimulus characteristics, which can be merged with the data.
Table 15 Effect of number of senses and number of meanings in Rodd et al. (2000, Experiment 2) and in virtual experiments with the same stimuli as those in the British Lexicon Project

** $p<.01, * p<.05,{ }^{+} p<.10$ or significant only in $F_{1}$ or $F_{2}$

\begin{tabular}{lll}
\hline & Original Experiment RTs & Virtual Experiment RTs \\
\hline Many meanings, few senses & 587 & 571 \\
Many meanings, many senses & 578 & 559 \\
One meaning, few senses & 586 & 560 \\
One meaning, many senses & 567 & 550 \\
Effect of number of meanings & 6 & 10 \\
Effect of number of senses & $14^{*}$ & $11^{+}$ \\
Interaction & 5 & 1 \\
\hline
\end{tabular}


Table 16 The feedforward and feedback consistency effects reported by Stone et al. (1997, Experiment 2) in the British Lexicon Project (BLP), in the English Lexicon Project (ELP), and combined. The first three columns show mean RTs, the final three columns show standardized RTs. The three final rows display the $p$-values of the effects

\begin{tabular}{|c|c|c|c|c|c|c|}
\hline & Original Experiment RTs & BLP RTs & ELP RTs & $z \mathrm{BLP}$ & $z \mathrm{ELP}$ & $z \mathrm{BLP}+z \mathrm{ELP}$ \\
\hline Feedforward consistent, feedback consistent & 732 & 574 & 634 & -.406 & -.505 & -.455 \\
\hline Feedforward consistent, feedback inconsistent & 778 & 624 & 718 & -.057 & -.248 & -.152 \\
\hline Feedforward inconsistent, feedback consistent & 780 & 598 & 669 & -.236 & -.386 & -.311 \\
\hline Feedforward inconsistent, feedback inconsistent & 770 & 617 & 690 & -.087 & -.292 & -.189 \\
\hline$p$ Feedforward consistency & .059 & .491 & .814 & .353 & .537 & .376 \\
\hline$p$ Feedback consistency & .086 & .005 & .003 & .001 & .005 & .001 \\
\hline$p$ Feedback $\times$ feedforward interaction & .129 & .189 & .066 & .182 & .186 & .137 \\
\hline
\end{tabular}

Item-level data

At the item level, there are 55,867 rows of data. For each stimulus (word or nonword), the following information is given.

- Spelling: the spelling of the stimulus as it was presented.

- Lexicality: whether the stimulus was a word (W) or a nonword $(\mathrm{N})$.

- RT: the average RT to the stimulus (correct trials only).

- Zscore: the average standardized RT. Standardized RTs were calculated separately for all levels of participant, block, and lexicality (e.g., all RTs to correct word trials in block 1 by participant 1 ).

- Accuracy: average accuracy for the stimulus.

- RT SD: standard deviation for the average RT.

- Zscore SD: standard deviation for the average $z$-score.

- Accuracy SD: standard deviation for the average accuracy.

Trial-level data

At the trial level, there are 2,240,940 rows of data. These are the raw data allowing everyone to run analyses as if they had collected the data themselves. For each trial, the following information is given.

- Environment: indicates which of the five computers the participant was using when the trial was recorded.

- Participant: identification number of the participant.

- Block: the number of the block in which the trial was presented.

- Order: the presentation order of the trial for the participant.

- Trial: the trial identification number.

- Spelling: the spelling of the stimulus.
- Lexicality: whether the stimulus was a word (W) or a nonword $(\mathrm{N})$.

- Response: the response to the stimulus. Word (W), nonword $(\mathrm{N})$, or time-out(T).

- Accuracy: 1 if the response matched the lexicality; otherwise, 0 .

- Previous accuracy: accuracy on the previous trial.

- $\quad$ RT: RT on the trial, with outliers and incorrect responses set to NA.

- $\quad$ RT raw: RT on the trial without cleaning.

- Previous RT: RT on the previous trial.

- Microsec error: the timing error given by the tscope software (in microseconds).

- Unix seconds: date and time in Unix seconds format (seconds elapsed since 1970).

- Unix microseconds: decimal part of unix seconds (in microseconds).

- Trial day: indicates how many trials the participant responded to since the day began (including the current trial).

- Trial session: indicates how many trials the participant responded to since the session began (including the current trial). A session expired after no response was given for $10 \mathrm{~min}$.

- Order in block: the presentation order of the trial in a block of 500 items.

- Order in subblock: the presentation order of the trial in a subblock of 100 items.

Stimulus characteristics

- Coltheart $N$ : the number of words of same length differing in one letter, computed over all word forms in the English CELEX lexical database (Baayen, Piepenbrock, \& Gulikers, 1995).

- OLD20: The average orthographic Levenshtein distance of the 20 most similar words, computed over all word forms in the English CELEX lexical database. 


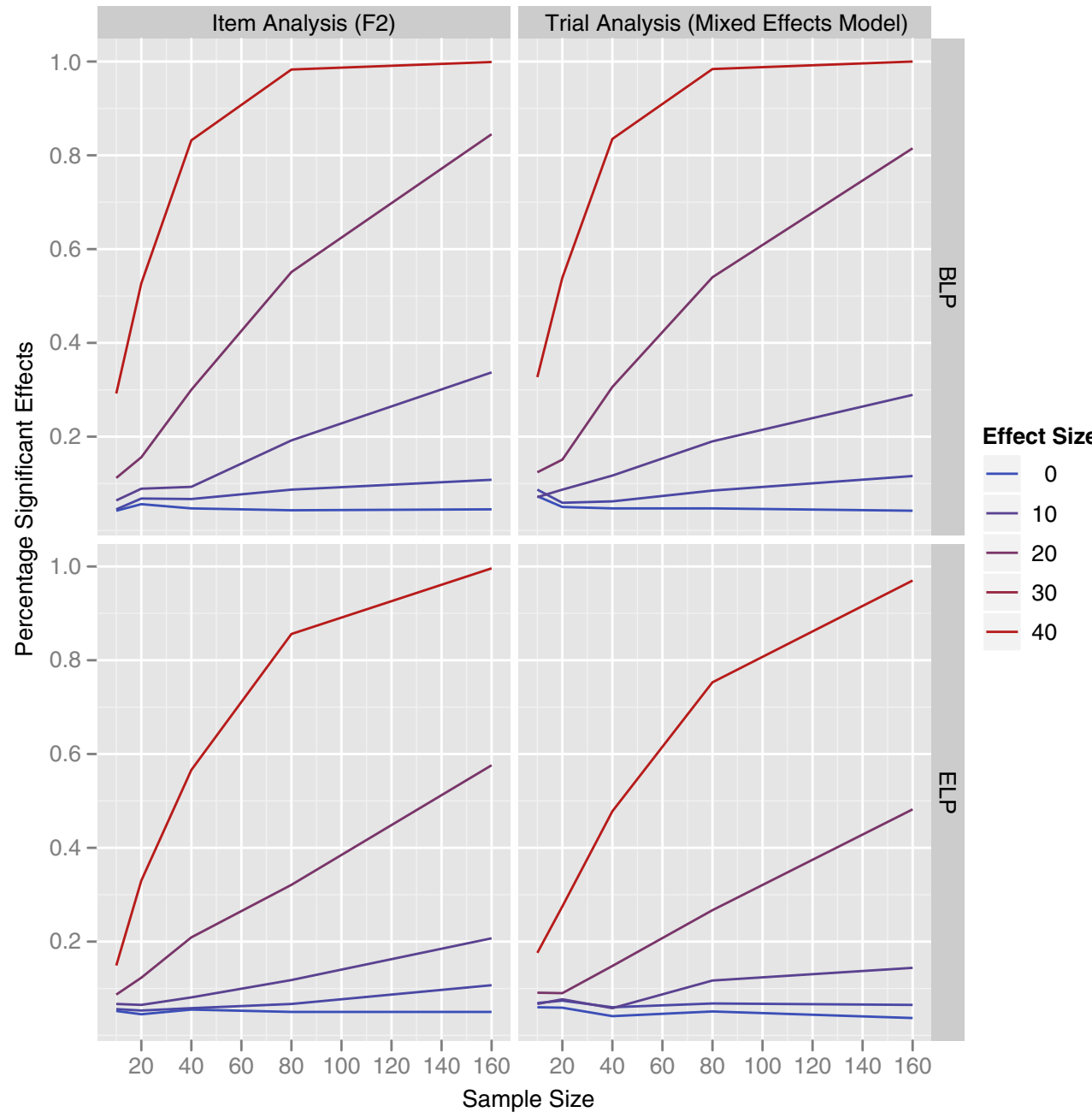

Fig. 6 Sample size required for finding an effect of a particular size (in milliseconds), derived from Monte Carlo simulation. For each combination of sample size $(n=10,20,40,80,160)$ and effect size $(0,5,10,20,40 \mathrm{~ms})$, we ran 1,000 simulations, each time taking two random samples of $n$ words from the database. The $y$-axis indicates the proportion of simulations in which the null hypothesis (no effect) was rejected (alpha $=.05$ ). Sample sizes at which sufficient power (.8) is reached for the British Lexicon Project are about $n=40$ for an effect of $40 \mathrm{~ms}$ and about $n=160$ for an effect of $20 \mathrm{~ms}$ in both types of analyses. For the English Lexicon Project, sufficient power is reached at about $n=70$ for an effect of $40 \mathrm{~ms}$ in the item analysis and about $n=100$ for an effect of $40 \mathrm{~ms}$ in the trial analysis
- CELEX frequency: Raw frequency of the stimulus as given by CELEX.

- CELEX CD: Contextual diversity (dispersion) of the stimulus in CELEX.

- CELEX frequency lemma: sum of the raw frequencies of all possible lemmas for the stimulus in CELEX.

- SUBTLEX frequency: raw frequency of the stimulus in the SUBTLEX-US database.

- SUBTLEX CD: contextual diversity of the stimulus in SUBTLEX-US.

- SUBTLEX frequency million: frequency per million of the stimulus in SUBTLEX-US.

- SUBTLEX CD pct: contextual diversity as a percentage of contexts of the stimulus in SUBTLEX-US.

- BNC frequency: raw frequency of the stimulus in $\mathrm{BNC}$.
- $\mathrm{BNC}$ frequency million: frequency per million of the stimulus in BNC.

- Summed monogram: sum of nonpositional letter frequencies, computed over all word forms in CELEX.

- Summed bigram: sum of nonpositional bigram frequencies.

- Summed trigram: sum of nonpositional trigram frequencies.

- Nletters: length of the stimulus in characters.

- Nsyl: length of the stimulus in syllables.

- Morphology: morphological status (e.g., monomorphemic, complex) of the form in CELEX. Different options are separated by a dot.

- Flection: flection (e.g., singular, plural) of the form in CELEX. Different options are separated by a dot.

- Synclass: syntactic class (e.g., verb, noun) of the form in CELEX. Different options are separated by a dot. 
Acknowledgements This research was made possible by an Odysseus grant awarded by the Government of Flanders (Belgium) to M.B. The authors thank Kevin Diependaele for making Fig. 1 and running the split-half reliability analysis and Pierre Courrieu for providing us with the ICC reliability analysis.

Open Access This article is distributed under the terms of the Creative Commons Attribution Noncommercial License which permits any noncommercial use, distribution, and reproduction in any medium, provided the original author(s) and source are credited.

\section{References}

Andrews, S. (1992). Frequency and neighborhood effects on lexical access: Lexical similarity or orthographic redundancy. Journal of Experimental Psychology: Learning, Memory, and Cognition, 18, 234-254.

Baayen, R. H., Davidson, D. J., \& Bates, D. M. (2008). Mixed-effects modeling with crossed random effects for subjects and items. Journal of Memory and Language, 59, 390-412.

Baayen, R. H., \& Milin, P. (in press). Analyzing reaction times. International Journal of Psychological Research.

Baayen, R. H., Piepenbrock, R., \& Gulikers, H. (1995). The CELEX Lexical Database [CD-ROM]. Philadelphia, PA: Linguistic Data Consortium.

Balota, D. A., Cortese, M. J., Sergent-Marshall, S. D., Spieler, D. H., \& Yap, M. J. (2004). Visual word recognition of single-syllable words. Journal of Experimental Psychology: General, 133, 283-316.

Balota, D. A., Yap, M. J., Cortese, M. J., Hutchison, K. A., Kessler, B., Loftis, B., et al. (2007). The English Lexicon Project. Behavior Research Methods, 39, 445-459.

Borowsky, R., \& Masson, M. E. J. (1996). Semantic ambiguity effects in word identification. Journal of Experimental Psychology: Learning, Memory, and Cognition, 22, 63-85.

Brysbaert, M., \& New, B. (2009). Moving beyond Kučera and Francis: A critical evaluation of current word frequency norms and the introduction of a new and improved word frequency measure for American English. Behavior Research Methods, 41, 977-990.

Chateau, D., \& Jared, D. (2000). Exposure to print and word recognition processes. Memory \& Cognition, 28, 143-153.

Chateau, D., \& Jared, D. (2003). Spelling-sound consistency effects in disyllabic word naming. Journal of Memory and Language, 48, 255-280.

Coltheart, M., Rastle, K., Perry, C., Langdon, R., \& Ziegler, J. (2001). DRC: A dual cascaded model of visual word recognition and reading aloud. Psychological Review, 108, 204-256.

Cortese, M. J., \& Khanna, M. M. (2007). Age of acquisition predicts naming and lexical-decision performance above and beyond 22 other predictor variables: An analysis of 2,342 words. Quarterly Journal of Experimental Psychology, 60, 1072-1082.

Cortese, M. J., \& Khanna, M. M. (2008). Age of acquisition ratings for 3,000 monosyllabic words. Behavior Research Methods, 40, 791-794.

Courrieu, P., Brand-D’Abrescia, M., Peereman, R., Spieler, D., \& Rey, A. (2011). Validated intraclass correlation statistics to test item performance models. Behavior Research Methods, 43, 37-55. doi:10.3758/s13428-010-0020-5.

Courrieu, P., \& Rey, A. (2011). Missing data imputation and corrected statistics for large-scale behavioral databases. Behavior Research Methods, 43, 310-330. doi:10.3758/s13428-011-0071-2.

Ferrand, L., New, B., Brysbaert, M., Keuleers, E., Bonin, P., Meot, A., et al. (2010). The French Lexicon Project: Lexical decision data for 38,840 French words and 38,840 pseudowords. Behavior Research Methods, 42, 488-496.

Gerhand, S., \& Barry, C. (1998). Word frequency effects in oral reading are not merely age-of-acquisition effects in disguise. Journal of Experimental Psychology: Learning, Memory, and Cognition, 24, 267-283.

Grainger, J., \& Jacobs, A. M. (1996). Orthographic processing in visual word recognition: A multiple read-out model. Psychological Review, 103, 518-565.

Hino, Y., \& Lupker, S. J. (1996). Effects of polysemy in lexical decision and naming: An alternative to lexical access accounts. Journal of Experimental Psychology: Human Perception and Performance, 22, 1331-1356.

Keuleers, E., \& Brysbaert, M. (2010). Wuggy: A multilingual pseudoword generator. Behavior Research Methods, 42, 627633.

Keuleers, E., Brysbaert, M., \& New, B. (2010a). SUBTLEX-NL: A new frequency measure for Dutch words based on film subtitles. Behavior Research Methods, 42, 643-650.

Keuleers, E., Diependaele, K., \& Brysbaert, M. (2010b). Practice effects in large-scale visual word recognition studies: A lexical decision study on 14,000 Dutch mono- and disyllabic words and nonwords. Frontiers in Language Sciences. Psychology, 1, 174. doi:10.3389/fpsyg.2010.00174.

Lemhofer, K., Dijkstra, T., Schriefers, H., Baayen, R. H., Grainger, J., \& Zwitserlood, P. (2008). Native language influences on word recognition in a second language: A megastudy. Journal of Experimental Psychology: Learning, Memory, and Cognition, 34, $12-31$.

Monsell, S., Doyle, M. C., \& Haggard, P. N. (1989). Effects of frequency on visual word recognition tasks: Where are they? Journal of Experimental Psychology: General, 118, 43-71.

Morrison, C. M., \& Ellis, A. W. (1995). Roles of word-frequency and age of acquisition in word naming and lexical decision. Journal of Experimental Psychology: Learning, Memory, and Cognition, 21, 116-133.

Pexman, P. M., Hino, Y., \& Lupker, S. J. (2004). Semantic ambiguity and the process of generating meaning from print. Journal of Experimental Psychology: Learning, Memory, and Cognition, 30, $1252-1270$.

Rey, A., \& Courrieu, P. (2010). Accounting for item variance in largescale databases. Frontiers in Psychology, 1, 200. doi:10.3389/ fpsyg.2010.00200.

Rodd, J., Gaskell, G., \& Marslen-Wilson, W. (2000). Making sense of semantic ambiguity: Semantic competition in lexical access. Journal of Memory and Language, 46, 245-266.

Sears, C. R., Hino, Y., \& Lupker, S. J. (1995). Neighborhood size and neighborhood frequency effects in word recognition. Journal of Experimental Psychology: Human Perception and Performance, 21, 876-900.

Sears, C. R., Siakaluk, P. D., Chow, V. C., \& Buchanan, L. (2008). Is there an effect of print exposure on the word frequency effect and the neighborhood size effect? Journal of Psycholinguistic Research, 37, 269-291.

Segui, J., \& Grainger, J. (1990). Priming word recognition with orthographic neighbors: Effects of relative prime target frequency. Journal of Experimental Psychology: Human Perception and Performance, 16, 65-76.

Seidenberg, M. S., \& Waters, G. S. (1989). Word recognition and naming: A mega study. Bulletin of the Psychonomic Society, 27, 489.

Seidenberg, M. S., Waters, G. S., Barnes, M. A., \& Tanenhaus, M. K. (1984). When does irregular spelling or pronunciation influence word recognition. Journal of Verbal Learning and Verbal Behavior, 23, 383-404.

Sibley, D. E., Kello, C. T., \& Seidenberg, M. S. (2009). Error, error everywhere: A look at megastudies of word reading. In $\mathrm{N}$. 
Taatgen \& H. Van Rijn (Eds.), Proceedings of the 31st Annual Conference of the Cognitive Science Society (pp. 1036-1041). Amsterdam: Cognitive Science Society.

Spieler, D. H., \& Balota, D. A. (1997). Bringing computational models of word naming down to the item level. Psychological Science, 8, 411-416.

Spieler, D. H., \& Balota, D. A. (2000). Factors influencing word naming in younger and older adults. Psychology and Aging, 15, 225-231.

Stevens, M., Lammertyn, J., Verbruggen, F., \& Vandierendonck, A. (2006). Tscope: A C library for programming cognitive experiments on the MS Windows platform. Behavior Research Methods, 38, 280-286.

Stone, G. O., Vanhoy, M., \& Van Orden, G. C. (1997). Perception is a two-way street: Feedforward and feedback phonology in visual word recognition. Journal of Memory and Language, 36, 337359.

Treiman, R., Mullennix, J., Bijeljac-Babic, R., \& Richmond-Welty, E. D. (1995). The special role of rimes in the description, use, and acquisition of English orthography. Journal of Experimental Psychology: General, 124, 107-136.

Wagenmakers, E. J., Ratcliff, R., Gomez, P. K., \& McKoon, G. (2008). A diffusion model account of criterion shifts in the lexical decision task. Journal of Memory and Language, 58, 140-159.

Yap, M. J., Balota, D. A., Tse, C. S., \& Besner, D. (2008). On the additive effects of stimulus quality and word frequency in lexical decision: Evidence for opposing interactive influences revealed by RT distributional analyses. Journal of Experimental Psychology: Learning, Memory, and Cognition, 34, 495-513.

Yates, M. (2005). Phonological neighbors speed visual word processing: Evidence from multiple tasks. Journal of Experimental Psychology: Learning, Memory, and Cognition, 31, 1385-1397.

Yates, M. (2009). Phonological neighborhood spread facilitates lexical decisions. Quarterly Journal of Experimental Psychology, 62, 1304-1314.

Yates, M., Locker, L., \& Simpson, G. B. (2004). The influence of phonological neighborhood on visual word perception. Psychonomic Bulletin \& Review, 11, 452-457. 